and in peripheral nerve myelin in the Guillain-Barré syndrome. ${ }^{5}$

Reye's syndrome ${ }^{6}$ usually follows varicella, influenza, or Coxsackie virus infection, but other viruses and agents have also been implicated. It presents with repeated attacks of vomiting, rapidly followed by delirium, seizures, and coma. There is diffuse cerebral oedema without any evidence of inflammation, and the liver and other organs show microvesicular fatty change. On electron microscopy, neurones and hepatocytes show distinctive mitochondrial changes. Epidemic myalgic encephalomyelitis, or postviral fatigue state, tends to occur after the same viral infections as Reye's syndrome. It has been recognised in sporadic cases or in epidemics for over 50 years. Most patients have increased IgG antibodies to Coxsackie viruses and some with chronic symptoms and signs show increases in specific IgM antibodies. ${ }^{7}$ Electrophysiological analyses of single muscle fibres in our own laboratory, and nuclear magnetic resonance studies of muscle in collaboration with Dr Radda at Oxford, have recently shown distinctive abnormalities. Furthermore, studies of lymphocyte subsets in the peripheral blood have shown increased numbers of suppressor cytotoxic lymphocytes and decreased numbers of helper cells. ${ }^{8}$ The relation in epidemic myalgic encephalomyelitis between immune deficiency, persistent infection by virus, and a possible enzyme defect is under investigation.

Many other neurological disorders, some inherited and some acquired, may be made worse by a viral infection. These include Refsum's disease, ${ }^{1}$ heredofamilial mononeuritis multiplex, ${ }^{9}$ neuralgic amyotrophy, ${ }^{10}$ the hereditary ataxias, ${ }^{11}$ and multiple sclerosis. ${ }^{2}$ Some patients may develop sensitisation to neural antigens before overt clinical disease develops, ${ }^{12}{ }^{13}$ and the viral infection may act through mechanisms which are related to the Shwartzman reaction. ${ }^{1415}$

The postviral syndromes have stimulated many theories to account for their features, the most important being an alteration in the regulation of the immune system. Viruses may induce immunosuppression in several ways: they may persist and multiply in lymphocytes-for example, measles can replicate in $T$ cells and Epstein-Barre virus in both $T$ and B cells; they may activate suppressor lymphocytes; or they may induce the release of suppressor factors, including interferon. They may also be associated with host reactions against self antigens and the development of autoimmune disease. Older explanations for this association centred on fusion of the virus with the cell membrane, release of sequestered antigen, or viral mimicry of host determinants. There is some experimental support for the suggestion that the virus envelope may incorporate host antigen and that this combination may activate $B$ lymphocytes to produce autoantibodies. ${ }^{16}$ Possibly viruses may combine with histocompatibility antigens, ${ }^{17}$ leading to recognition by $T$ cells and an immune reaction to host tissue. Immune complexes of virus and antibody, especially when formed in situ, are a known cause of tissue damage. Finally, viruses to which the patient is already sensitised may act as the precipitating agent in a Shwartzman type reaction. ${ }^{15}$

Consultant Neurologist and Reader in Neurology,

Peter O Behan

Institute of Neurological Sciences,

Southern General Hospital

Glasgow G51 4TF

${ }^{1}$ Refsum S. Heredopathia atactica polyneuritiformis. In: Vinken PJ, Bruyn GW, eds. System disorders and atrophies. Amsterdam: NorthHolland Publishing Company, 1975:181-229. (Handbook of clinical neurology. Vol 21.)

${ }^{2}$ McAlpine D. Some aspects of the natural history: precipitating and aggravating factors. In: McAlpine D, Lumsden CE, Acheson ED, eds. Multiple sclerosis. Edinburgh: Churchill Livingstone, 1972:99-131.
${ }^{3}$ Corey LC, Rubin RJ. Reye's syndrome 1974; an epidemiologic assessment. In: Pollack JD, ed. Reye's syndrome. New York: Grune and Stratton, 1975:175-87.

4 Scott TFM. Postinfectious and vaccinal encephalitis. Med Clin North Am 1967;51:701-17.

${ }^{5}$ Poser CM, Behan PO. Late onset of Guillain-Barré syndrome. 7 Neuroimmunol $1982 ; 3: 27-41$.

${ }^{6}$ Mowat AP. Reye's syndrome: 20 years on. Br Med 7 1983;286:1999-2001.

'Behan PO, Behan WMH. Epidemic myalgic encephalomyelitis. In: Rose FC, ed. Clinical neuroepidemiology. Tunbridge Wells: Pitman Medical, 1980:374-83.

${ }^{8}$ Behan PO, Behan WMH. Immunotherapy in chronic neurological disorders of presumed viral aetiology. In: Behan PO, Spreafico F, eds. Neuroimmunology. New York: Raven Press (in press).

9 Taylor RA. Heredofamilial mononeuritis multiplex with brachial predilection. Brain 1960;83:113-37.

${ }^{10}$ Elliott FA. Diseases of the peripheral nerves. In: Clinical neurology. Philadelphia: W B Saunders, 1964:575-88.

11 Greenfield JG. System degenerations of the cerebellum, brain stem and spinal cord. In: Blackwood W, McMenemey WH, Meyer A, Norman RM, Russell DS, eds. Greenfield's neuropathology. Baltimore: Williams and Wilkins Company, 1966:581-601.

12 Walls RS, Philcox DV, Cullis CL. Cellular hypersensitivity to brain antigen in children of a family with hereditary ataxia. 7 Neurol Neurosurg Psychiatry 1979;42:203-7.

13 Alvord EC, Hsu PC, Thron R. Leukocyte sensitivity to brain fractions in neurological diseases. Arch Neurol 1974;30:296-9.

14 De Weck AL, Frey JR, Geleick H. Immunologic specificity of the localized Shwartzman phenomenon induced in guinea pigs by simple chemical haptens. F Immunol 1968;100:1-6.

${ }^{5}$ Hjort PF, Rapaport SI. The Shwartzman reaction: pathogenetic mechanisms and clinical manifestations. Annu Rev Med 1965;16:135-68.

16 Allison AC. Autoimmune diseases: concepts of pathogenesis and control. In: Talal N, ed. Autoimmunity. Genetic, immunologic, virologic, and clinical aspects. New York: Academic Press, 1977:91-139.

' Zinkernagel RM, Dunlop MBC, Blanden RV, Doherty PC, Shreffler DC. $\mathrm{H}-2$ compatibility requirement for virus-specific T-cell-mediated cytolysis. Evaluation of the role of $\mathrm{H}-21$ region and non- $\mathrm{H}-2$ genes in regulating immune response. $\mathcal{F} \operatorname{Exp}$ Med 1976;144:519-32.

\section{Principles for the future of the special hospitals}

Nowhere in its new report on the future of the special hospitals ${ }^{1}$ does the Royal College of Psychiatrists' special committee tell us what it thinks should be these hospitals' philosophy, but principles can be sifted out. One explicit statement of principle that the report does make is that we will continue to need special hospitals, which is just as well as contracts have recently been signed for the rebuilding of Broadmoor.

The first principle should be that as few people as possible are detained in the special hospitals and that those who are detained should be in for as short a time as possible. Although the special hospitals are not nearly as unpleasant as people imagine, to have been a special hospital patient is the worst stigma that our society has to offer, and nobody should be in a special hospital unless he or she needs to be there. The psychiatrists who work in the special hospitals know that many of their patients do not need to be there, but they cannot know for sure who those patients are. Those responsible for discharges are between the devil and the deep blue sea: currently they are being pilloried for keeping patients who do not need to be there, but just as often they are criticised for releasing patients who then commit violent offences. Clearly continuing research is needed to refine the criteria for both admission and discharge.

What is sure is that "one in eight patients in the special hospital are waiting to go, their discharge or transfer having been agreed," and that one in three of these patients have been waiting to be transferred for over two years. The report insists that this is a problem that requires "priority attention ... not only from the Department of Health and Social Security but from psychiatrists, nursing staff and their trade unions, and 
local health authorities." This is a problem not so much of the special hospitals but more of the NHS hospitals that have lost the skills of dealing with potentially difficult patients. But a problem that does belong with special hospitals is their lack of skill in rehabilitation, and the report praises the rehabilitative endeavours of Balderton Hospital on behalf of Rampton and suggests that all the special hospitals establish such a unit.

The second major principle for special hospitals should be to try to make these abnormal places as normal as possible. Security is obviously important, but as the Boynton report on Rampton said it is wrong to subject patients to a higher degree of security than is clinically necessary. ${ }^{2}$ A secure perimeter is enough for most patients, and seclusion should be kept to a minimum. ${ }^{3}$ Within the hospitals patients should be allowed free movement, to wear their own clothes, to have access to outside media, and to receive and send uncensored letters, and the sexes should be able to mix. Another of the report's recommendations that will help to normalise the special hospitals is that general practitioners from outside should provide for the physical care of the patients.

A third principle that goes together with normalising the special hospitals is that they should be as open as possible. Staff should not be required to sign the Official Secrets Act, and, as well as local doctors coming in to treat the patients, the local community should be involved with the hospital, and local dignitaries might take part in its management. Links with academic institutions should be encouraged, and the Mental Health Act Commission, which will be established under the Mental Health Act 1983 to protect detained patients, should be welcomed. Journalists, too, should be encouraged to visit the special hospitals not just when somebody escapes, and they should help the public recognise that most people in the special hospitals are not dangerous while in them and that only a few of those released ever commit violent crimes. (One study has shown that in the last 18 years only $1^{\circ}$ " of those discharged from Broadmoor have committed homicide, ${ }^{4}$ and another study of 180 patients subject to restriction orders showed that after release $84^{\circ}$, had not reoffended in any way..$^{5}$ )
A final principle that can be deduced from the report is that special hospitals should take only those patients who are thought to be treatable. If everybody who is mentally impaired is thought to be treatable then this should present no problem, but the very introduction of the word implies that some people are not treatable. These untreatable people are presumably to be left where they are to cope as they can, and the place that they are most likely to find themselves is in prison. Our unpleasant and grossly overcrowded prisons are no place for those who are mentally impaired but considered untreatable, and maybe the special hospitals should accept that they must be asylums as well as places of treatment. This asylum function need not conflict with the cardinal principle of keeping people out of special hospitals as much as possible.

The report says relatively little about the relations between the special hospitals and the prisons, except to note that in recent years prison medical officers have put forward fewer cases for consideration for transfer to the special hospitals. This may be happening, the report suggests, because the prison doctors are fed up with their cases not being accepted, but when this decline is put together with the fact that the proportion of patients being transferred to special hospitals rather than NHS hospitals is rising it can suggest only that there are more and more mentally ill people languishing in our prisons. A closer relationship between doctors in prisons and those in special hospitals, perhaps even to the extent of them being employed by the same authority, could only benefit the mentally ill in prison.

${ }^{1}$ Special Committee on the Special Hospitals. The future of the special hospitals. London: Royal College of Psychiatrists, 1983.

${ }^{2}$ Department of Health and Social Security. Report of the review of Rampton Hospital. London: HMSO, 1980. (Cmnd 8073.)

${ }^{3}$ Wilkinson G. Locking up patients with psychiatric illness. Br Med f 1983; 286:581-2.

4 Tidmarsh D. Implications from research studies. In: Hamilton JR, Freeman H, eds. Dangerousness; psychiatric assessment and management. London: Gaskell, 1982.

${ }^{5}$ Aarvold Committee. Report on the review of procedures for the discharge and supervision of psychiatric patients subject to special restrictions. London: HMSO, 1973.

\section{Regular Review}

\section{Anorexia nervosa}

\section{A H CRISP}

Those who have written extensively about anorexia nervosa over the past 50 years must be baffled by the present insistence that the condition is only now being truly discovered and that it has also become much more common. It was carefully described and reported in English works of over 300 years ago and given further credibility through the descriptions by Lasegue $^{1}$ and Gull. ${ }^{2}$ The syndrome attracted attention in France at the turn of the century, ${ }^{34}$ in Britain in the $1930 \mathrm{~s},{ }^{56}$ in the United States in the 1940s, and in Germany ${ }^{7} 8$ and Scandinavia ${ }^{910}$ in the 1950 s and thereafter. Despite the scholarly report by Kaufman and Heiman ${ }^{11}$ anorexia nervosa was neglected in the United States for two decades apart from the pioneering work of psychoanalysts such as Bruch ${ }^{12} 13$ and Sours ${ }^{14}$ and the remarkable collection of cases at the Mayo Clinic, first reported by Berkman ${ }^{15}$ and now numbering several thousands. Bliss and Branch in $1960^{16}$ wrote an admirably critical monograph on the condition but it may have impaired the recognition of anorexia nervosa in North America by its mistaken insistence that the disorder was no more than a syndrome of "nervous malnutrition."

Very little can be said about the prevalence of the condition, but from the limited information available there are at least 